\title{
Les derniers chasseurs-cueilleurs en Normandie
}

\section{Sylvène Michel}

\section{OpenEdition}

\section{Journals}

Édition électronique

URL : https://journals.openedition.org/rao/1862

DOI : 10.4000/rao.1862

ISBN : 978-2-7535-2790-4

ISSN : 1775-3732

Éditeur

Presses universitaires de Rennes

Édition imprimée

Date de publication : 30 décembre 2012

Pagination : 319

ISBN : 978-2-7535-2641-9

ISSN : 0767-709X

\section{Référence électronique}

Sylvène Michel, "Les derniers chasseurs-cueilleurs en Normandie », Revue archéologique de l'Ouest [En ligne], 29 | 2012, mis en ligne le 30 décembre 2012, consulté le 24 juillet 2021. URL : http:// journals.openedition.org/rao/1862 ; DOI : https://doi.org/10.4000/rao.1862

Ce document a été généré automatiquement le 24 juillet 2021.

@ Presses universitaires de Rennes 


\title{
Les derniers chasseurs-cueilleurs en Normandie
}

\author{
Sylvène Michel
}

\section{RÉFÉRENCE}

Ghesquière E., 2011 - Les derniers chasseurs-cueilleurs en Normandie, OREP Éditions, «Archéologies normandes », 48 p. (ISBN 978-2-8151-0071-7, 8,50€).

1 Cet ouvrage, qui participe à la collection «Archéologies normandes » récemment développée par les éditions OREP, est consacré au Mésolithique normand replacé dans son contexte national. Ce petit manuel généraliste et abordable par un plus grand nombre grâce à une synthèse efficace et à un prix minime, présente de manière plutôt ludique cette période encore souvent méconnue du grand public.

2 Emmanuel Ghesquière développe successivement quatre grandes thématiques et offre ainsi une vision complète de ces groupes mésolithiques, en s'appuyant sur des données récemment acquises. En guise d'introduction, l'auteur, responsable de fouilles archéologiques à l'Inrap, insiste à juste titre sur l'apport conséquent de l'archéologie préventive, tout en rendant également hommage aux prospecteurs et aux chercheurs qui ont été à l'origine de l'étude du Mésolithique normand. Le premier chapitre présente les changements climatiques et environnementaux auxquels ces sociétés sont confrontées, en rappelant notamment les conséquences en termes de disponibilité et de stratégies d'acquisition des ressources alimentaires. Ce dernier point amène ensuite l'auteur à parler des modes d'habitat et des systèmes de mobilité de ces chasseurscueilleurs. La troisième partie concerne quant à elle la culture matérielle, et plus précisément les industries lithiques qui ont mieux résisté aux aléas du temps que les vestiges organiques. L'auteur en profite pour évoquer alors l'identité culturelle de ces groupes et l'ensemble des entités stylistiques qu'il déduit de l'étude des types d'armature. Pour compléter l'exposé, les questions des sépultures et de l'art de ces 
sociétés sont enfin abordées, avant de conclure sur les contacts entre les derniers chasseurs-cueilleurs et les premiers agriculteurs normands.

3 L'ouvrage livre régulièrement de petites synthèses sur des sites qui servent de références régionales depuis plusieurs décennies ou qui sont en passe de le devenir. Audelà de ces exemples régionaux qui rendent les propos développés très concrets, l'auteur aborde cette thématique en évoquant, ne serait-ce que par l'illustration, les méthodes de fouille, l'interdisciplinarité sur laquelle repose l'archéologie et certaines théories générales sur le Mésolithique français. Les lecteurs apprécieront sans doute également les exemples ethnologiques variés auxquels se réfère l'auteur. Le tout forme un volume très dynamique, presque filmographique tant l'iconographie est abondante et de qualité. On plonge donc facilement dans la lecture de cet ouvrage rédigé avec clarté et engouement. Si cet enthousiasme se double parfois de quelques imprécisions ou de points de vue qui ne font pas l'unanimité parmi les mésolithiciens (en témoignent respectivement l'attribution chrono-culturelle prématurée et erronée d'une sépulture d'Alizay, et les interprétations relatives à la céramique de la Hoguette), il aura assurément le mérite d'attiser la curiosité du grand public vis-à-vis des groupes mésolithiques.

\section{AUTEURS}

\section{SYLVÈNE MICHEL}

Inrap Grand-Ouest - UMR 6566-CReAAH 